\title{
Bioresorbable everolimus-eluting vascular scaffold in patients with ST-segment elevation myocardial infarction: Optical coherence tomography evaluation and clinical outcomes
}

\author{
Janusz Kochman ${ }^{1}$, Mariusz Tomaniak ${ }^{1}$, Arkadiusz Pietrasik ${ }^{1}$, Łukasz Kołtowski ${ }^{1}$, \\ Adam Rdzanek ${ }^{1}$, Zenon Huczek ${ }^{1}$, Tomasz Mazurek ${ }^{1}$, Jacek Jąkała ${ }^{2}$, Aldona Ząbek² \\ Jacek Legutko ${ }^{3}$, Wacław Kochman ${ }^{4}$, Krzysztof J. Filipiak ${ }^{1}$ \\ ${ }^{1} 1^{\text {st }}$ Department of Cardiology, Medical University of Warsaw, Warsaw, Poland \\ ${ }^{2}$ Krakow Cardiovascular Research Institute, Krakow, Poland \\ ${ }^{3}$ Department of Interventional Cardiology, Jagiellonian University, Krakow, Poland \\ ${ }^{4}$ Faculty of Health Sciences, Medical University of Gdansk, Gdansk, Poland
}

\begin{abstract}
Background: Bioresorbable vascular scaffold (BVS) implantation is a new, promising treatment method of coronary artery disease. Preliminary data in patients with stable angina are encouraging. However, the utility of BVS was not sufficiently evaluated in the setting of acute thrombotic lesions. The aim of this study was an optical coherence tomography (OCT) assessment of acute procedural result of the everolimus-eluting BVS implantation in patients with ST segment elevation myocardial infarction (STEMI) and evaluation of mid-term clinical outcomes.
\end{abstract}

Methods: OCT examination was conducted in 23 STEMI patients who underwent primary angioplasty with BVS implantation. Off-line qualitative and quantitative coronary angiography and OCT analyses were performed by an independent core laboratory.

Results: Successful procedural and clinical results were achieved in $95.7 \%$ of patients, and device success was observed in all patients. In OCT evaluation, most of the struts $(95.4 \pm$ $\pm 7.96 \%$ ) were well apposed, $4.6 \pm 5.71 \%$ were classified as malapposed. The final minimum lumen diameter was $2.6 \pm 0.35 \mathrm{~mm}$, minimum scaffold area was $6.9 \pm 1.54 \mathrm{~mm}^{2}$ and final residual stenosis was $8.8 \pm 24.37 \%$. Edge dissections were found in $3(7.7 \%)$ lesions. Median follow-up period was 229 (interquartile range 199-248) days. One myocardial infarction, due to sub-acute stent thrombosis, occurred in a patient who discontinued pharmacotherapy.

Conclusions: The study shows that everolimus-eluting BVS implantation in STEMI is safe and feasible. The OCT evaluation confirmed excellent acute performance with appropriate scaffold expansion and low rate of malapposition. (Cardiol J 2015; 22, 3: 315-322)

Key words: bioresorbable vascular scaffold, optical coherence tomography, ST elevation myocardial infarction, percutaneous coronary interventions

Address for correspondence: Janusz Kochman, MD, $\mathrm{PhD}, 1^{\text {st }}$ Department of Cardiology, Medical University of Warsaw, ul. Żwirki i Wigury 61, 02-091 Warszawa, Poland, e-mail: jkochman@wum.edu.pl

Received: 29.07.2014 Accepted: 31.10.2014 


\section{Introduction}

Everolimus-eluting bioresorbable vascular scaffold (BVS) is an interesting new technology recently applied in the treatment of coronary artery lesions that might overcome the limitations of the currently used drug eluting stents (DES). Favorable features of BVS involve restoration of native vessel vasomotion, prevention of expansive remodeling, improvement of plaque stability, late lumen enlargement and potential avoidance of long-term complications, such as stent thrombosis, restenosis and neoatherosclerosis [1-4]. These beneficial effects were confirmed in preliminary studies in patients with stable coronary artery disease [4-12]. However, the utility of BVS was not sufficiently evaluated in the setting of acute coronary syndromes characterized by a different plaque pathomorphology. Acute thrombothic lesions with a large thrombus burden predispose to distal embolization and no-reflow syndrome, as well as to increased risk of stent malapposition. The latter phenomenon is associated with the dissolution of the thrombus sequestrated between the BVS struts and the vessel wall $[13,14]$. There are only few reports with a comprehensive optical coherence tomography (OCT) evaluation of the BVS implantation in this group of patients $[15,16]$. To add more data to the current limited body of evidence, we performed a pilot study with a qualitative and quantitative OCT examination to assess vessels' response to the implanted BVS and the performance of the new device in culprit lesions in patients presenting with ST segment elevation myocardial infarction (STEMI).

\section{Methods}

In this single-center, prospective registry, 23 patients with STEMI, who underwent primary percutaneous coronary intervention (pPCI) with implantation of at least one BVS, ABSORB ${ }^{\mathrm{TM}}$ (Abbott Vascular, Santa Clara, CA, USA) between March and August 2013 at the $1^{\text {st }}$ Department of Cardiology at Warsaw Medical University, were included. Enrolled patients were older than 18 years, had chest pain below $12 \mathrm{~h}$ and met electrocardiographic criteria of STEMI according to the European Society of Cardiology guidelines [17]. Angiographic inclusion criteria involved $d e$ novo native coronary artery lesions in vessels with diameter between 2.5 and $3.8 \mathrm{~mm}$ (compatible with the use of a 2.5, 3.0 or $3.5 \mathrm{~mm}$ BVS). Major clinical exclusion criteria were: cardiogenic shock, prehospital cardiac arrest, severe heart failure with left ventricular ejection fraction $(\mathrm{LVEF})<30 \%$, contraindications for antiplatelet therapy, known contrast intolerance, pregnancy, malignant disease and participation in other investigational drug and device studies. Angiographic exclusion criteria were: left main coronary artery lesions, multivessel disease qualified for surgery, lesions involving a large side branch (diameter $>2.5 \mathrm{~mm}$ ), massive calcifications, and arteries $<2.5 \mathrm{~mm}$ in diameter.

The protocol was approved by the local Ethics Committee and all patients gave written informed consent before inclusion.

Dual antiplatelet therapy was planned to be continued for 12 months after pPCI according to the current guidelines on the management of patients presenting with STEMI [17]. The administration of glycoprotein IIb/IIIa inhibitors was left to the operator's discretion.

Detailed characteristics of BVS implanted in this study have been previously described [18-20]. Briefly, the scaffold is made of a polymer backbone of poly-L-lactide (PLLA) covered with a thin layer of a 1:1 mixture of poly-D,L-lactide polymer (PDLLA). Both materials are completely bioresorbable within approximately 2 to 3 years. The ester bonds of these polymers are hydrolyzed into lactate and its oligomers are further metabolized in the Krebs cycles. Antiproliferative drug everolimus is integrated in this balloon-expandable device in the concentration of $100 \mathrm{mg} / \mathrm{cm}^{2}$ of the scaffold and $80 \%$ of the whole everolimus load is eluted within the first 30 days.

\section{Coronary angiography and OCT analyses}

Coronary angiography and pPCI were performed by experienced interventional cardiologists. Post procedure OCT examination was conducted with a commercially available $\mathrm{C} 7 \mathrm{OCT}$ imaging system with Dragonfly ${ }^{\circledR}$ image wires (LightLab Imaging Inc., Westford, Massachusetts, US). Off-line qualitative and quantitative coronary angiography (QCA) and OCT analyses were performed by an independent core laboratory (Krakow Cardiovascular Research Institute, Krakow, Poland). The QCA analysis was performed using Cardiovascular Angiography Analysis System 5.7.1 (Pie Medical Imaging Systems, Maastricht, the Netherlands) with the methodology already reported [21], and included: lesion length, minimum luminal diameter (MLD), reference vessel diameter (RVD), maximal diameter at segment $\left(\mathrm{D}_{\max }\right)$, percentage of diameter stenosis (\%DS), angiographic measures of perfusion (Thrombolysis In Myocardial Infarction [TIMI], and myocardial blush grade [MBG]). The thrombus grade was assessed based upon 


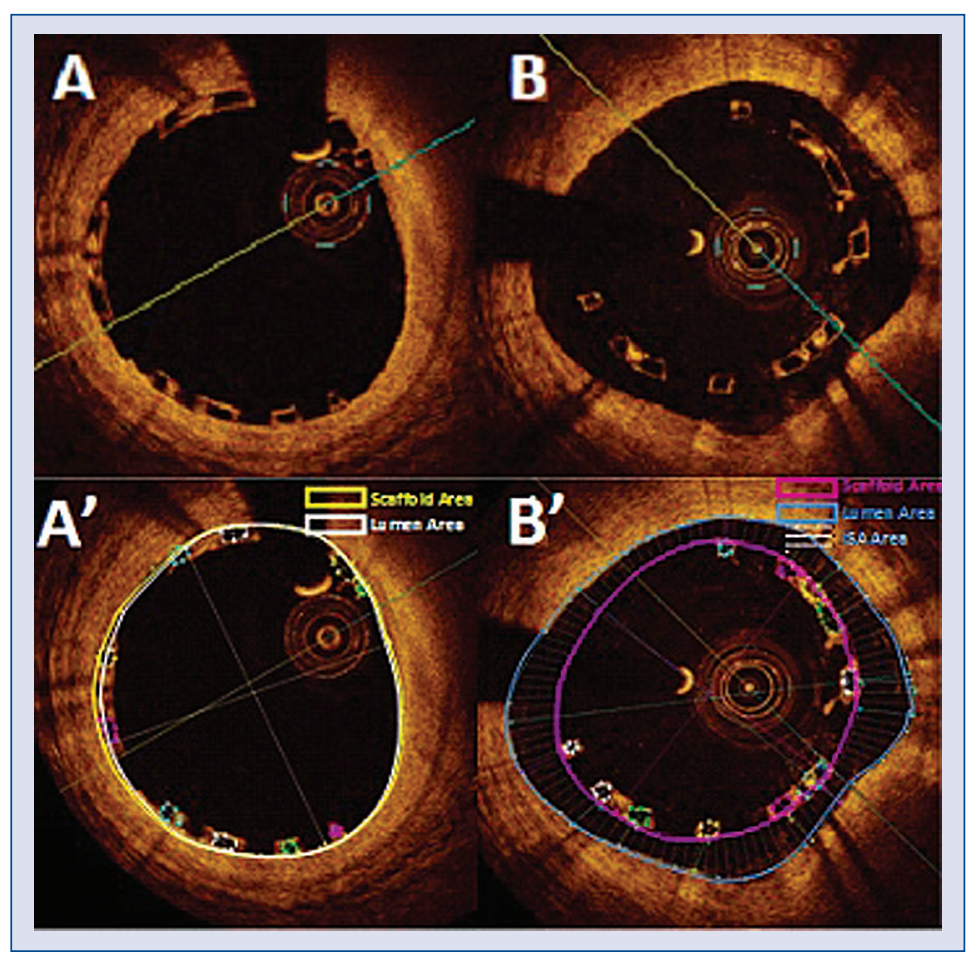

Figure 1. Methodology of optical coherence tomography images analysis; A. Complete apposition of struts and absence of tissue prolapse; B. Scaffold malapposition; A', B'. Optical coherence images with delineated shapes of scaffold area, lumen area and incomplete scaffold area (ISA Area).

the previously described 6 -grade scale [22]). The $\mathrm{D}_{\max }$ represents the two single largest values of reference diameters observed in the segments proximal or distal to the lesion. The RVD is the virtual reference diameter measured at the site of the MLD prior to the scaffold implantation. Acute gain was calculated as post-procedural MLD minus pre-procedural MLD, and in case of pre-procedural total occlusion of culprit vessel, the MLD value was considered equal to zero.

The OCT measurements using the LightLab OCT imaging proprietary software were done by analysts blinded to the angiographic data. The quantitative and qualitative OCT assessment was based on previously described methodology [4, 23-25].

Scaffold analyses were performed in 1-mm longitudinal intervals. Quantitative measurements were performed at the abluminal surface of the struts and included lumen and scaffold areas and diameters. The OCT evaluation also involved the calculation of lumen areas and diameters at reference sites. Residual area stenosis was calculated as: (1 - [minimum scaffold area/maximum lumen area at reference site] $) \times 100$. Strut and vessel wall interaction was defined in every single scaffold strut as complete apposition or malapposition (Figs. 1-3).
Success rates were defined as in previous studies with BVS implantation [15, 16]. Device success was described as the presence of residual diameter stenosis $<30 \%$ of the segment of the culprit lesion, covered by the BVS, assessed by angiographic visual estimation. Bailout stenting was not considered a device failure. Procedural success was defined as a device success with final TIMI 3 flow and no major periprocedural complications, such as coronary perforation requiring pericardial drainage, emergent coronary artery bypass graft or flow-limiting dissection. Clinical success was defined as procedural success and no in-hospital major adverse cardiac events (MACE) including death, stroke/transient ischemic attack and new myocardial infarction (MI).

Patients were scheduled for a 30-day, 6- and 12 -month clinical evaluation. MACE incidence rates were recorded involving all-cause death, non-fatal MI, target lesion revascularization (TLR), target vessel revascularization (TVR), non-TVR and scaffold thrombosis. Additionally, angiographic and OCT evaluation were planned at the $12^{\text {th }}$ and $24^{\text {th }}$ month after the index procedure. MI and scaffold thrombosis were defined according to the Academic Research Consortium definition [26]. Statistical 


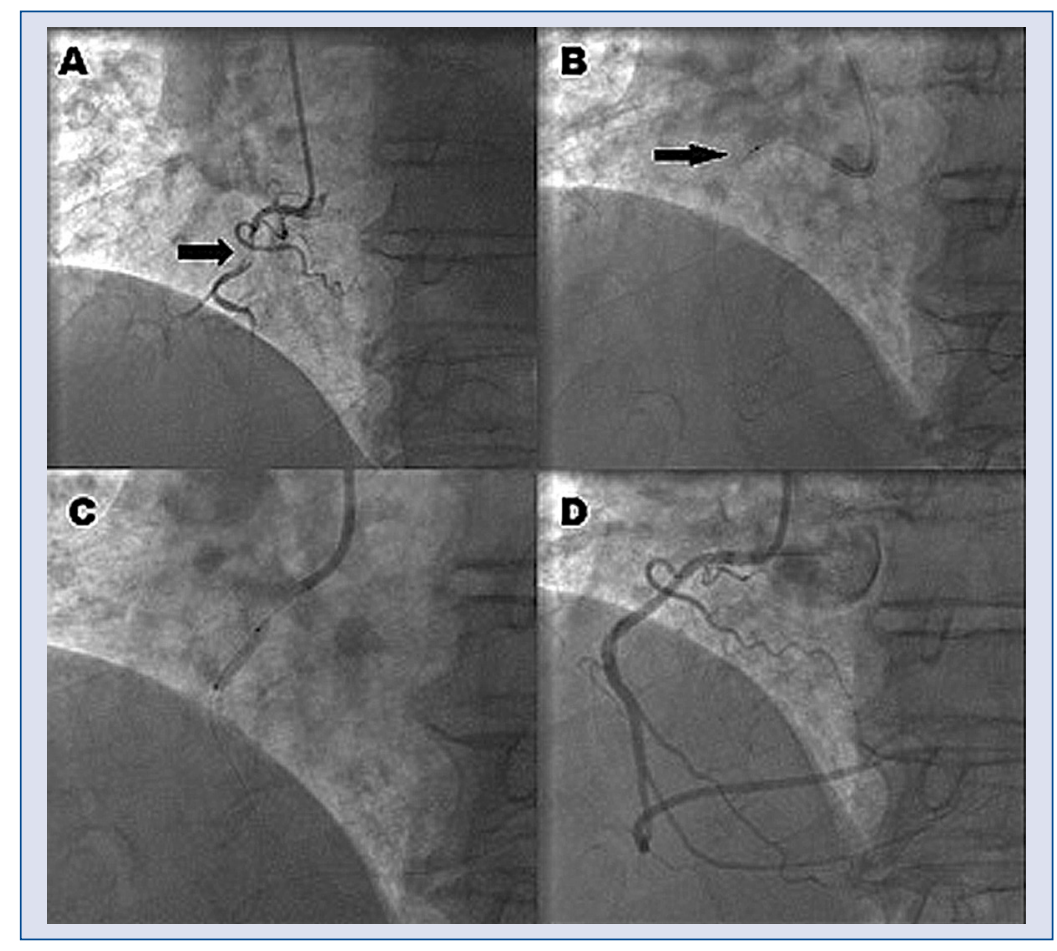

Figure 2. Bioresorbable vascular scaffold implantation in a culprit right coronary artery (RCA); A. Coronary angiography demonstrating a culprit lesion in the proximal-RCA (arrow); B. Manual aspiration thrombectomy - a radiopaque marker at distal end of aspiration catheter (arrow); C. Predilatation with a 2.0/15 mm semi-compliant balloon; D. Angiography following implantation of a $3.0 / 18 \mathrm{~mm}$ bioresorbable vascular scaffold.

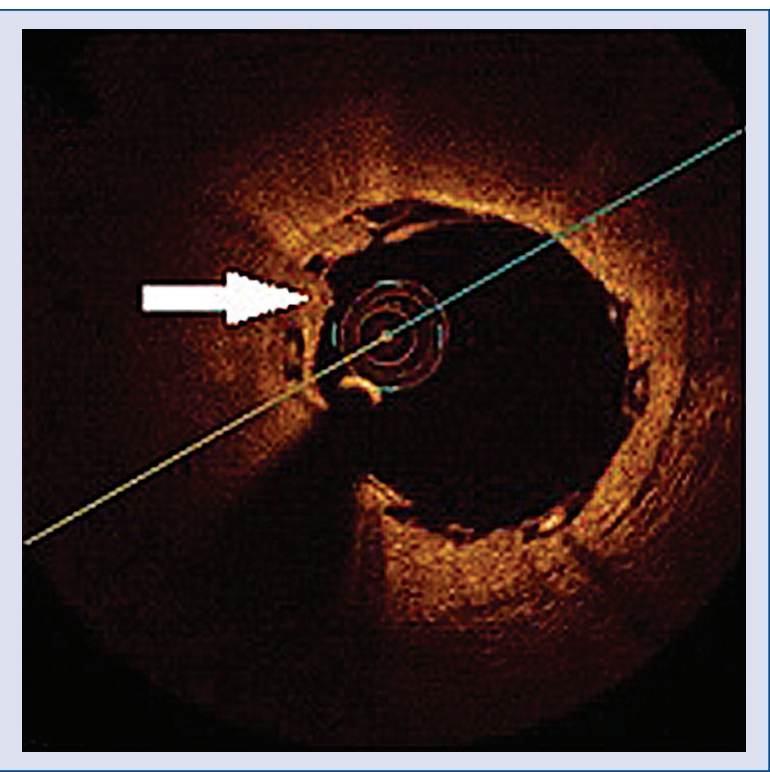

Figure 3. Optical coherence tomography image following bioresorbable vascular scaffold implantation confirm complete apposition of the scaffold and reveal some thrombus protrusions through scaffold's struts (arrow). analysis was performed using the JMP software, version 9.0.0 (SAS Institute Cary, NC, USA). All values are expressed as mean \pm standard deviation (continuous variables) or as count and percentage (categorical variables).

\section{Results}

The patient baseline characteristics are presented in Table 1 . A total of 23 patients with STEMI were prospectively enrolled. Two patients received 2 scaffolds in different, non-overlapping sites (second culprit lesion). Another 3 patients required 2 overlapping scaffolds due to edge dissection, eventually 28 BVS were implanted in 23 vessels including: left anterior descending artery (17.4\%, $\mathrm{n}=4)$, circumflex artery $(17.4 \%, \mathrm{n}=4)$, obtuse marginal branch $(4.4 \%, \mathrm{n}=1)$ and right coronary artery $(60.8 \%, \mathrm{n}=14)$. Procedural and clinical success were achieved in $95.7 \%$ of the study population and device success was observed in the entire group. Manual aspiration thrombectomy was performed in 13 (56.5\%) cases with totally occluded culprit artery (TIMI 0). Direct scaffold implantation 
Table 1. Baseline characteristics ( $n=23$ patients).

\begin{tabular}{lc}
\hline Age [years] & $58.5 \pm 8.7$ \\
Male gender & $16(69.6 \%)$ \\
Diabetes & $5(21.7 \%)$ \\
Hypertension requiring medication & $15(65.2 \%)$ \\
Hyperlipidemia requiring medication & $20(87.0 \%)$ \\
Current smokers & $14(60.9 \%)$ \\
Chronic obstructive pulmonary & $1(4.3 \%)$ \\
disease & \\
Prior MI & $1(4.3 \%)$ \\
Prior CABG & $1(4.3 \%)$ \\
Peripheral vascular disease & $1(4.3 \%)$ \\
Kidney disease (< eGFR) & $2(8.7 \%)$ \\
\hline
\end{tabular}

CABG - coronary artery bypass graft; eGFR - estimated glomerular filtration rate; $\mathrm{MI}$ - myocardial infarction

Table 2. Baseline angiographic data.

\begin{tabular}{|c|c|}
\hline \multicolumn{2}{|l|}{ Target vessel: } \\
\hline LAD & $4(17.4 \%)$ \\
\hline $\mathrm{Cx}$ & $4(17.4 \%)$ \\
\hline OM & $1(4.3 \%)$ \\
\hline RCA & $14(60.9 \%)$ \\
\hline Lesion length [mm] & $12.31 \pm 4.7$ \\
\hline Minimal luminal diameter [mm] & $0.42 \pm 0.66$ \\
\hline Diameter stenosis [\%] & $86.88 \pm 18.92$ \\
\hline Reference vessel diameter [mm] & $3.06 \pm 0.65$ \\
\hline $\mathrm{D}_{\max \operatorname{prox}}[\mathrm{mm}]$ & $3.24 \pm 0.71$ \\
\hline $\mathrm{D}_{\max \text { dist }}[\mathrm{mm}]$ & $2.92 \pm 0.68$ \\
\hline \multicolumn{2}{|l|}{ TIMI at baseline: } \\
\hline 0 & $13(56.5 \%)$ \\
\hline 1 & $1(4.3 \%)$ \\
\hline 2 & $7(30.4 \%)$ \\
\hline 3 & $2(8.7 \%)$ \\
\hline \multicolumn{2}{|l|}{ MBG at baseline*: } \\
\hline 0 & $1(5.0 \%)$ \\
\hline 1 & $5(25.0 \%)$ \\
\hline 2 & $6(30.0 \%)$ \\
\hline 3 & $8(40.0 \%)$ \\
\hline \multicolumn{2}{|l|}{ Thrombus grade at baseline ${ }^{* *}$ : } \\
\hline 0 & $5(20.0 \%)$ \\
\hline 1 & $0(0.0 \%)$ \\
\hline 2 & $1(4.0 \%)$ \\
\hline 3 & $1(4.0 \%)$ \\
\hline 4 & $5(20.0 \%)$ \\
\hline 5 & $13(52.0 \%)$ \\
\hline
\end{tabular}

*Analysis was performed for 20 patients with recorded angiograms allowing for the MBG assessment; ${ }^{* *}$ Analysis was performed for 25 lesions; LAD - left anterior descending; Cx - left circumflex; $\mathrm{OM}$ - obtuse marginal branch; RCA — right coronary artery; $\mathrm{D}_{\text {max }}$ - ob - maximal proximal diameter; $\mathrm{D}_{\text {max dist }}$ - maximal distal diameter; TIMI — Thrombolysis In Myocardial Infarction; MBG myocardial blush grade was done in $5(21.7 \%)$ patients; $15(65.2 \%)$ patients required postdilatation. Final \%DS was $11.4 \pm$ $\pm 9.45 \%$. TIMI 3 flow and MBG 3 were achieved in $95.7 \%$ and $78.3 \%$ of patients, respectively. Baseline angiographic characteristics and procedural data are shown in Tables 2 and 3.

The OCT examination was performed in all patients after optimal angiographic result was achieved. In $5(21.7 \%)$ cases, the operator decided to perform additional postdilatation because of scaffold malapposition and/or device underexpansion revealed by OCT.

OCT data from 3 patients were excluded from further evaluation due to insufficient quality of obtained images. The final OCT data of $20 \mathrm{pa}-$ tients ( 25 scaffolds) are presented in Table 4 . The scaffold length by OCT was $23.4 \pm 8.42 \mathrm{~mm}$ that was comparable with QCA measurements $(21.8 \pm$ $\pm 8.75 \mathrm{~mm}$ ). Similarly, the results of in-scaffold MLD did not differ in both imaging modalities (2.5 \pm $\pm 0.40 \mathrm{~mm}$ and $2.6 \pm 0.35 \mathrm{~mm}$, for OCT and QCA, respectively). Minimum scaffold area in OCT was $6.9 \pm 1.54 \mathrm{~mm}^{2}$ and final residual area stenosis was $8.8 \pm 24.37 \%$. Edge dissections were found in $3(12.0 \%)$ lesions - in all cases in proximal reference. The scaffold expansion was symmetrical and no disruptions or discontinuities of scaffold structure, such as overhanging struts, were observed. Out of 4,019 analyzed struts, $95.4 \pm 7.96 \%$ were completely apposed, malapposition was found in $4.6 \pm 5.71 \%$. There were only $2(8.0 \%)$ scaffolds in which more than $5 \%$ of malapposed struts were found. Qualitative OCT assessment immediately after implantation revealed a preserved box appearance in all struts.

OCT intra- and inter-observer variability analysis of lumen area and scaffold area performed in a single region of interest were good. For intraobserver, mean difference was $-0.04 \pm 0.15 \mathrm{~mm}^{2}$ $(-0.56 \% \pm 2.05 \%)$ for lumen area and $-0.03 \pm$ $\pm 0.16 \mathrm{~mm}^{2}(0.32 \% \pm 2.07 \%)$ for scaffold area. For inter-observer, mean difference was $0.24 \pm 0.35 \mathrm{~mm}^{2}$ $(2.69 \% \pm 3.79 \%)$ for lumen area and $-0.28 \pm$ $\pm 0.24 \mathrm{~mm}^{2}(2.90 \% \pm 2.54 \%)$ for scaffold area.

Complete follow-up was available in $21(91.3 \%)$ patients with a median time of 229 days (interquartile range 199-248 days) - the results are presented in Table 5. One patient who discontinued pharmacotherapy had a non-fatal MI due to sub-acute stent thrombosis on the $9^{\text {th }}$ day after BVS implantation (5 days after discontinuation of antiplatelet drugs). The TLR (and TVR) in this case involved manual aspiration thrombectomy, abciximab infusion and plain old balloon angioplasty, 
Table 3. Procedural data.

\begin{tabular}{|c|c|}
\hline \multicolumn{2}{|l|}{ TIMI at final: } \\
\hline 3 & $22(95.7 \%)$ \\
\hline 2 & $1(4.3 \%)$ \\
\hline TFC at final [Frames] & $22 \pm 7.62$ \\
\hline cTFC at final [Frames] & $20.08 \pm 6.31$ \\
\hline \multicolumn{2}{|l|}{ MBG at final: } \\
\hline 0 & $1(4.3 \%)$ \\
\hline 1 & $1(4.3 \%)$ \\
\hline 2 & $3(13.1 \%)$ \\
\hline 3 & $18(78.3 \%)$ \\
\hline \multicolumn{2}{|l|}{ Thrombus grade at final*: } \\
\hline 0 & $24(96.0 \%)$ \\
\hline 1 & $1(4.0 \%)$ \\
\hline $2-5$ & $0(0.0 \%)$ \\
\hline Side branch closure & $1(4.3 \%)$ \\
\hline Distal embolization & $1(4.3 \%)$ \\
\hline Total number of scaffolds & 28 \\
\hline \multicolumn{2}{|l|}{ Number of scaffolds per lesion: } \\
\hline 1 & $22(88.0 \%)$ \\
\hline 2 & $3(12.0 \%)$ \\
\hline Scaffold length [mm] & $21.12 \pm 8.4$ \\
\hline $\begin{array}{l}\text { Minimal luminal diameter } \\
\text { in scaffold }[\mathrm{mm}]\end{array}$ & $2.55 \pm 0.4$ \\
\hline Acute gain [mm] & $2.13 \pm 0.75$ \\
\hline Residual diameter stenosis [\%] & $11.44 \pm 9.04$ \\
\hline Reference vessel diameter [mm] & $2.91 \pm 0.53$ \\
\hline Direct stenting & $5(21.7 \%)$ \\
\hline Predilatation & $20(87.0 \%)$ \\
\hline Manual aspiration thrombectomy & $13(56.5 \%)$ \\
\hline Maximum dilating pressure [atm] & $17.4 \pm 3.0$ \\
\hline Postdilatation & $15(65.2 \%)$ \\
\hline Mean door-to-balloon time [min] & $31.1 \pm 19.3$ \\
\hline Transradial procedure & $21(91.3 \%)$ \\
\hline \multicolumn{2}{|l|}{ Medication: } \\
\hline Aspirin & $23(100.0 \%)$ \\
\hline Clopidogrel & $22(95.7 \%)$ \\
\hline Prasugrel & $1(4.3 \%)$ \\
\hline Unfractionated heparin & $23(100.0 \%)$ \\
\hline Use of GP IIb/IIla inhibitors & $20(87.0 \%)$ \\
\hline Peak CK-MB [ng/mL] & $148.7 \pm 184.7$ \\
\hline Peak troponin I [ng/mL] & $49.0 \pm 57.2$ \\
\hline
\end{tabular}

*Analysis was performed for 25 lesions; CK-MB - creatinine kinase muscle-brain fraction; GP - glycoprotein; MBG - myocardial blush grade; TIMI - Thrombolysis In Myocardial Infarction; TFC - TIMI frame count; cTFC — corrected TIMI frame count
Table 4. Optical coherence tomography data.

\begin{tabular}{|c|c|}
\hline Total number of analyzed struts & 4019 \\
\hline Mean discernible struts per BVS & $182.68 \pm 90.45$ \\
\hline \multicolumn{2}{|l|}{ Strut/vessel wall interaction: } \\
\hline Complete strut apposition [\%] & $95.36 \pm 7.96$ \\
\hline Malapposed strut [\%] & $4.64 \pm 5.71$ \\
\hline \multicolumn{2}{|l|}{ Quantitative assessment of a scaffold: } \\
\hline Scaffold length [mm] & $23.39 \pm 8.42$ \\
\hline Minimum lumen diameter [mm] & $2.56 \pm 0.35$ \\
\hline Minimum LA $\left[\mathrm{mm}^{2}\right]$ & $6.52 \pm 1.46$ \\
\hline Mean LA [mm²] & $7.96 \pm 1.63$ \\
\hline Minimum scaffold area $\left[\mathrm{mm}^{2}\right]$ & $6.90 \pm 1.54$ \\
\hline Mean scaffold area $\left[\mathrm{mm}^{2}\right]$ & $8.17 \pm 1.63$ \\
\hline Mean ISA area $\left[\mathrm{mm}^{2}\right]$ & $0.38 \pm 0.64$ \\
\hline Residual area stenosis [\%] & $8.80 \pm 24.37$ \\
\hline Edge dissection & $3(12.0 \%)$ \\
\hline \multicolumn{2}{|l|}{$\begin{array}{l}\text { Quantitative assessment } \\
\text { of a reference sites: }\end{array}$} \\
\hline Maximum LA in distal $\left[\mathrm{mm}^{2}\right]$ & $8.06 \pm 3.30$ \\
\hline Mean LA in distal $\left[\mathrm{mm}^{2}\right]$ & $6.71 \pm 3.20$ \\
\hline Maximum LA in proximal $\left[\mathrm{mm}^{2}\right]$ & $9.94 \pm 2.98$ \\
\hline Mean LA in proximal $\left[\mathrm{mm}^{2}\right]$ & $8.66 \pm 3.00$ \\
\hline $\begin{array}{l}\text { Scaffolds with at least } \\
1 \text { malapposed strut }\end{array}$ & $16(64.0 \%)$ \\
\hline $\begin{array}{l}\text { Scaffolds with > 5\% } \\
\text { malapposed struts }\end{array}$ & $2(8.0 \%)$ \\
\hline
\end{tabular}

BVS - biodegradable vascular scaffold; ISA — incomplete scaffold area; LA - lumen area

Table 5. Clinical outcomes ( $n=23$ patients).

\begin{tabular}{lc}
\hline Median follow-up time [days] (IQR) & $229(199-248)$ \\
Death & $0(0.0 \%)$ \\
Any MI: & $1(4.3 \%)$ \\
Target-vessel MI: & $1(4.3 \%)$ \\
Q-wave MI & $1(4.4 \%)$ \\
Non Q-wave MI & $0(0.0 \%)$ \\
Non target-vessel MI: & $0(0.0 \%)$ \\
$\quad$ Q-wave MI & $0(0.0 \%)$ \\
$\quad$ Non Q-wave MI & $0(0.0 \%)$ \\
Target lesion revascularization & $1(4.3 \%)$ \\
Target vessel revascularization & $1(4.3 \%)$ \\
Non-target vessel revascularization & $3(13.0 \%)$ \\
Definite or probable scaffold & $1(4.3 \%)$ \\
thrombosis & $47.5 \pm 8.1$ \\
LVEF at discharge [\%] & \\
\hline IQR - interquartile range; MI - myocardial infarction; LVEF - left \\
ventricular ejection fraction
\end{tabular}


with good final angiographic result (TIMI 3). His LVEF dropped from $50 \%$, directly after the primary index procedure to $38 \%$. Two patients had non-TVR angioplasty with DES implantation. There were no other MACE observed in this study.

\section{Discussion}

The principal finding of this study with precise qualitative and quantitative protocol-based scaffold analysis in OCT is that BVS implantation in patients with STEMI is safe and effective, which was clearly demonstrated by excellent device, procedural and clinical success rates associated with over 95\% of completely apposed scaffolds' struts, and low incidence of residual stenosis and edge dissections.

Dilletti et al. [15] reported $22.6 \%$ of scaffolds with more than $5 \%$ of malapposed struts, which is regarded as significant malapposition according to commonly used definition in previous studies $[27,28]$. In patients with acute coronary syndromes, treated with the currently recommended DES implantation, the rate of malapposed stents reached up to $30 \%[28,29]$. In our study, only $8.0 \%$ of scaffolds were found to be significantly malapposed. Such a low rate of malapposition may be partially related to the small number of study patients. However, the more likely explanation is the fact that the OCT guidance used in all patients influenced the operator's performance, leading to additional balloon postdilatations in $21.7 \%$ of cases. Although the BVS implantation technique employs the same principles utilized in conventional metallic stent angioplasty, the adequate assessment of optimal expansion of the device, based solely upon angiography, may be difficult due to radiolucent features of the BVS.

A relatively high thrombus burden (grade 4 or 5 in $72 \%$ ) was observed in our group before BVS implantation. It has been hypothesized that due to the higher profile of BVS, its placement in acute thrombotic lesions might require a more intense lesion preparation compared with standard metallic stents, which may increase the risk of distal embolization, no-reflow phenomenon and reduced final TIMI flow [15]. Nevertheless, TIMI 3 flow and MBG rate were high and comparable with those reported in previous studies on pPCI with stents [30-32]. Distal embolization occurred only in $1(4.3 \%)$ case and no-reflow phenomenon in none. These findings are in line with recently published studies in STEMI population treated with the same type of BVS $[15,16]$.
STEMI is an independent predictor for acute or late stent thrombosis [33-35]. In our study, one sub-acute stent thrombosis was observed. However, due to the fact that it occurred 5 days after the patient had stopped (on his own) dual antiplatelet therapy, it seems to be a consequence of inappropriate platelet inhibition rather than a device-related event.

Sequestration of thrombus burden between the struts and vessel wall may lead to late scaffold malapposition and/or scaffold thrombosis in case of its resolution before the struts dissolution. As a consequence, the turbulent blood flow around scaffold's struts and activation of platelet aggregation on the surface of struts might facilitate new thrombus formation. However, the assessment of the risk of possible late acquired malapposition and scaffold thrombosis requires serial OCT examinations.

The results from the prospective registry and currently available body of evidence provide valuable clinical insights in favor of everolimus-eluting BVS implantation in STEMI population. However, the current body of evidence is still limited due to a small number of patients and does not allow to draw any firm conclusions regarding wider application of BVS in pPCI in everyday clinical practice.

\section{Limitations of the study}

The main limitation of this study is the low number of patients, strict angiographic and clinical inclusion/exclusion criteria and its non-randomized design. The report is of preliminary character and further investigations with a head-to-head comparison of BVS with the current standard of care are needed to assess the role of this device in the treatment of patients with STEMI.

\section{Conclusions}

The presented results demonstrated that BVS implantation in selected STEMI patients is safe and feasible. The acute OCT evaluation confirmed excellent performance with appropriate scaffold expansion and low rate of malapposition. Further randomized controlled trials are necessary to confirm the safety and efficacy of BVS in this group of patients.

\section{Conflict of interest: None declared}

\section{References}

1. Brugaletta S, Radu MD, Garcia-Garcia HM et al. Circumferential evaluation of the neointima by optical coherence tomography after ABSORB bioresorbable vascular scaf-fold implantation: Can the scaffold cap the plaque? Atherosclerosis, 2012; 221: 106-112. 
2. Brugaletta S, Gomez-Lara J, Serruys PW et al. Bruining N. Serial in vivo intravascular ultrasound-based echogenicity changes of everolimus-eluting bioresorbable vascular scaffold during the first 12 months after implantation insights from the ABSORB B trial. J Am Coll Cardiol Cardiovasc Interv, 2011; 4: 1281-1289.

3. Iqbal J, Onuma Y, Orniston J, Abizaid et al. Bioresorbable scaffolds: Rationale, current status, challenges, and future. Eur Heart J 2014; 35: 765-776.

4. Serruys PW, Onuma Y, Dudek D et al. Evaluation of the second generation of a bioresorbable everolimus- eluting vascular scaffold for the treatment of de novo coronary artery stenosis: 12-month clinical and imaging outcomes. J Am Coll Cardiol, 2011; 58: 1578-1588.

5. Ormiston JA, Serruys PW, Onuma Y et al. First serial assessment at 6 months and 2 years of the second generation of absorb everolimuseluting bioresorbable vascular scaffold: A multi-imaging modality study. Circ Cardiovasc Interv, 2012; 5: 620-632.

6. Dudek D, Onuma Y, Ormiston JA et al. Four-year clinical follow-up of the ABSORB everolimus-eluting bioresorbable vascular scaffold in patients with de novo coronary artery disease: The ABSORB trial. EuroIntervention, 2012; 7: 1060-1061.

7. Gomez-Lara J, Brugaletta S, Farooq V et al. Head-to-head comparison of the neointimal response between metallic and bioresorbable everolimus-eluting scaffolds using optical coherence tomography. J Am Coll Cardiol Cardiovasc Interv, 2011; 4: 1271-1280.

8. Diletti R, Farooq V, Girasis C et al. Clinical and intravascular imaging outcomes at 1 and 2 years after implantation of absorb everolimus eluting bioresorbable vascular scaffolds in small vessels. Late lumen enlargement: Does bioresorption matter with small vessel size? Insight from the ABSORB cohort B trial. Heart, 2013; 99: 98-105.

9. Diletti R, Serruys PW, Farooq V et al. ABSORB II randomized controlled trial: A clinical evaluation to compare the safety, efficacy, and performance of the Absorb everolimus-eluting bioresorbable vascular scaffold system against the XIENCE everolimus-eluting coronary stent system in the treatment of subjects with ischemic heart disease caused by de novo native coronary artery lesions: Rationale and study design. Am Heart J, 2012; 164: 654-663.

10. Onuma Y, Serruys PW, Ormiston JA et al. Three-year results of clinical follow-up after a bioresorbable everolimus-eluting scaffold in patients with de novo coronary artery disease: The ABSORB trial. EuroIntervention, 2010; 6: 447-453.

11. Serruys PW, Ormiston JA, Onuma Y et al. A bioabsorbable everolimuseluting coronary stent system (ABSORB): 2-year outcomes and results from multiple imaging methods. Lancet, 2009; 373: 897-910.

12. Diletti R, Onuma Y, Farooq V et al. 6-month clinical outcomes following implantation of the bioresorbable everolimus-eluting vascular scaffold in vessels smaller or larger than $2.5 \mathrm{~mm}$. J Am Coll Cardiol, 2011; 58: $258-264$.

13. Hong MK, Mintz GS, Lee CW et al. Incidence, mechanism, predictors, and long-term prognosis of late stent malapposition after bare-metal stent implantation. Circulation, 2004; 109: 881-886.

14. Hong MK, Mintz GS, Lee CW et al. Late stent malapposition after drug-eluting stent implantation: An intravascular ultrasound analysis with long-term follow-up. Circulation, 2006; 113: 414-419.

15. Diletti R, Karanasos A, Muramatsu T et al. Everolimus-eluting bioresorbable vascular scaffolds for treatment of patients presenting with ST-segment elevation myocardial infarction: BVS STEMI first study. Eur Heart J. 2014; 35: 777-786.

16. Kocka V, Maly M, Tousek P et al. Bioresorbable vascular scaffolds in acute ST-segment elevation myocardial infarction: A prospective multicentre study 'Prague 19'. Eur Heart J, 2014; 35: 787-794.

17. Steg PG, James SK, Atar D et al. Task Force on the management of ST-segment elevation acute myocardial infarction of the European Society of Cardiology (ESC). ESC guidelines for the management of acute myocardial infarction in patients presenting with ST-segment elevation. Eur Heart J, 2012; 33: 2569-2619.

18. OnumaY, Serruys PW, Perkins LE et al. Intracoronary optical coherence tomography and histology at 1 month and 2,3 , and 4 years after implantation of everolimus-eluting bioresorbable vascular scaffolds in a porcine coronary arterymodel: An attempt to decipher the human optical coherence tomography images in the ABSORB trial. Circulation, 2010; 122: 2288-2300.

19. Onuma Y, Serruys PW. Bioresorbable scaffold: The advent of a new era in percutaneous coronary and peripheral revascularization? Circulation, 2011; 123: 779-797.

20. Oberhauser JP, Hossainy S, Rapoza RJ. Design principles and performance of bioresorbable polymeric vascular scaffolds. EuroIntervention, 2009; 5 (suppl. F): F15-F22.

21. Tuinenburg JC, Koning G, Hekking E et al. American College of Cardiology/European Society of Cardiology International Study of Angiographic Data Compression Phase II: The effects of varying JPEG data compression levels on the quantitative assessment of the degree of stenosis in digital coronary angiography. Joint Photographic Experts Group. J Am Coll Cardiol, 2000; 35: 1380-1387.

22. Sianos G, Papafaklis MI, Daemen J et al. Angiographic stent thrombosis after routine use of drug-eluting stents in ST-segment elevation myocardial infarction: The importance of thrombus burden. J Am Coll Cardiol, 2007; 50: 573-583.

23. Serruys PW, Onuma Y, Ormiston JA et al. Evaluation of the second generation of a bioresorbable everolimus drug-eluting vascular scaffold for treatment of de novo coronary artery stenosis: Six-month clinical and imaging outcomes. Circulation, 2010; 122: 2301-2312.

24. Gomez-Lara J, Brugaletta S, Diletti R et al. A comparative assessment by optical coherence tomography of the performance of the first and second generation of the everolimus-eluting bioresorbable vascular scaffolds. Eur Heart J, 2011; 32: 294-304.

25. Gomez-Lara J, Radu M, Brugaletta S et al. Serial analysis of the malapposed and uncovered struts of the newgeneration of everolimus-eluting bioresorbable scaffold with optical coherence tomography. J Am Coll Cardiol Cardiovasc Interv, 2011; 4: 992-1001.

26. Cutlip DE, Windecker S, Mehran R et al. Academic Research C. Clinical end points in coronary stent trials: A case for standardized definitions. Circulation, 2007; 115: 2344-2351.

27. Barlis P, Regar E, Serruys PW et al. An optical coherence tomography study of a biodegradable vs. durable polymer-coated limus-eluting stent: A LEADERS trial sub-study. Eur Heart J, 2010; 31: 165-176.

28. van Geuns RJ, Tamburino C, Fajadet J et al. Self-expanding versus balloon-expandable stents in acute myocardial infarction: Results from the APPOSITION II study: Self-expanding stents in ST-segment elevation myocardial infarction. J Am Coll Cardiol Cardiovasc Interv, 2012; 5: 1209-1219.

29. Onuma Y, Thuesen L, van Geuns RJ et al. Randomized study to assess the effect of thrombus aspiration on flow area in patients with ST-elevation myocardial infarction: An optical frequency domain imaging study: TROFI trial. Eur Heart J, 2013; 34: 1050-1060.

30. Raber L, Kelbaek H, Ostojic M et al. Effect of biolimus-eluting stents with biodegradable polymer vs bare-metal stents on cardiovascular events among patients with acute myocardial infarction: The COMFORTABLE AMI randomized trial. JAMA, 2012; 308: 777-787.

31. Sabate $\mathrm{M}$, Cequier A, Iniguez A et al. Everolimus-eluting stent versus bare-metal stent in ST-segment elevation myocardial infarction (EXAMINATION): 1 year results of a randomised controlled trial. Lancet, 2012; 380: 1482-1490.

32. De Luca G, van't Hof A, de Boer MJ et al. Impaired Myocardial perfusion is a major explanation of the poor outcome observed in patients undergoing primary angioplasty for ST-segment-elevation myocardial infarction and signs of heart failure. Circulation, 2004; 109: 958-961.

33. Daemen J, Wenaweser P, Tsuchida K et al. Early and late coronary stent thrombosis of sirolimus-eluting and paclitaxel-eluting stents in routine clinical practice: Data from a large two-institutional cohort study. Lancet, 2007; 369: 667-678.

34. Park DW, Park SW, Park KH et al. Frequency of and risk factors for stent thrombosis after drug-eluting stent implantation during longterm follow-up. Am J Cardiol, 2006; 98: 352-356.

35. Wenaweser P, Daemen J, Zwahlen $\mathrm{M}$ et al. Incidence and correlates of drug-eluting stent thrombosis in routine clinical practice. 4-year results from a large 2-institutional cohort study. J Am Coll Cardiol, 2008; 52 : $1134-1140$. 